\title{
ANALISIS PERHITUNGAN TARIF BIAYA PELABUHAN KAPAL NASIONAL DAN KAPAL ASING DI PELABUHAN TANJUNG PRIOK
}

\section{CALCULATION ANALYSIS OF PORT FEE OF NATIONAL VESSELS AND FOREIGN VESSELS IN TANJUNG PRIOK PORT}

\author{
a,1* Vivian Karim Ladesi, Anindiya Fitriana ${ }^{\text {b,2 }}$ \\ a Dosen Pembimbing Prodi D III Transportasi, Jl. Rawamangun Muka, Jakarta Timur, Indonesia \\ ${ }^{\mathrm{b}}$ Mahasiswa Prodi D III Transportasi, Jl. Rawamangun Muka, Jakarta Timur, Indonesia \\ 1* Vivian_Ladesi@unj.ac.id, ${ }^{2}$ Anindiyaf49@gmail.com \\ *corresponding e-mail: transportasiunj@yahoo.co.id
}

\begin{abstract}
The selection of this Final Project aims to analyze the calculation of the cost tariff for the port of national ships and foreign ships at the Port of Tanjung Priok and the factors that influence the comparison of the port cost rates for national ships and foreign ships to be used as an evaluation material for the port and determine the port rates so that service services to be more efficient and economical. The method used in the preparation of this final project is the literature method, interview study and field observation study. The tariff for port services must have a balance between the amount of the tariff and the level of service received by service users, including safety, security, smoothness and comfort. In encouraging the investment climate and creating efficient and competitive port service tariffs, it is necessary to rearrange the types of structures, categories and mechanisms for determining port service tariffs. One of the factors causing the comparison of port cost rates which causes foreign ship port rates to be higher is the service factor because services at the port are not efficient so that to get customer satisfaction / port service users still charge a higher tariff for each activity.
\end{abstract}

Keywords : Costs, Rates, Factors

\begin{abstract}
ABSTRAK
Pemilihan Tugas Akhir ini bertujuan untuk menganalisis perhitungan tarif biaya pelabuhan kapal nasional dan kapal asing di Pelabuhan Tanjung Priok dan faktor faktor yang mempengaruhi perbandingan tarif biaya pelabuhan untuk kapal nasional dan kapal asing guna menjadi sebagai bahan evaluasi pihak pelabuhan dan menentukan tarif pelabuhan sehingga pelayanan jasa pelayanan menjadi lebih efisien dan ekonomis. Metode yang digunakan dalam penyusunan Tugas Akhir ini adalah metode kepustakaan, studi interview dan studi observasi lapangan. Tarif jasa kepelabuhanan harus ada keseimbangan antara besaran tarif dengan tingkat pelayanan yang diterima oleh pengguna jasa, meliputi keselamatan, keamanan, kelancaran dan kenyamanan. Dalam mendorong iklim investasi dan menciptakan tarif jasa kepelabuhanan yang efisien dan kompetitif perlu dilakukan penataan kembali jenis struktur, golongan dan
\end{abstract}


mekanismen penetapan tarif jasa kepelabuhanan. faktor penyebab perbandingan tarif biaya pelabuhan yang menyebabkan tarif pelabuhan kapal asing lebih tinggi salah satunya ialah faktor pelayanan karena pelayanan di pelabuhan belum efisien sehingga untuk mendapat kepuasan pelanggan / pengguna jasa pelabuhan masih mengenakan tarif yang lebih besar untuk setiap kegiatannya.

Kata kunci : Biaya, Tarif, Faktor.

\section{A. Pendahuluan}

Tarif adalah harga jasa dari setiap jenis pelayanan yang terdapat didalam pelabuhan (port pricing). Tarif jasa pelabuhan terjadi karena ada pihak yang memberikan/menyediakan pelayanan (oleh penyelenggara pelabuhan) oleh sebab itu tarif harus jelas besarannya, jenis pelayanan yang diberikan/disediakan dan bagaimana pemberlakuannya. Pada dasarnya pelayanan yang diberikan oleh pelabuhan adalah pelayanan terhadap kapal dan pelayanan terhadap muatan (barang dan penumpang).Secara teoritis, sebagai bagian dari mata rantai transportasi laut, fungsi pelabuhan adalah tempat pertemuan (interface) dua moda angkutan atau lebih serta interface berbagai kepentingan yang saling terkait. Atas dasar latar belakang itulah penulis mencoba untuk menganalisis apa saja pembiayaan yang timbul ketika kapal sandar dalam melakukan proses bongkar atau muat di suatu dermaga. Kemudian penulis juga mencoba menganalisis hasil yang di capai dengan metode yang digunakan tersebut dan selanjutnya mencoba memberikan perbandingan biaya pelabuhan yang timbul saat kapal sandar yang dilakukan oleh kapal nasional dan kapal asing. Dan dalam hal ini penulis memilih Pelabuhan Tanjung Priok sebagai tempat untuk mengamati dan menganalisa hal-hal tersebut di atas.

\section{B. Metode Penelitian}

Metode penilitian yang digunakan pada penelitian ini adalah metode deskritif kualitatif yaitu berupa wawancara dan analisis data mengenai tarif baya pelabuhan yang berlaku saat ini serta faktor yang menyebabkan pembeda tarif pelabuhan anatar kapal nasional dan kapal asing di pelabuhan tanjung priok.

\section{Hasil dan Pembahasan}

Menurut PM 72 tahun 2017 Tentang Jenis, Struktur, Golongan dan Mekanisme penetapan tarif jasa kepelabuhanan menyebutkan bahwa tarif pelayanan jasa Kapal yang melakukan kegiatan angkutan laut dalam negeri dikenakan tarif jasa kepelabuhanan dalam mata uang Rupiah (Rp). Sedangkan Tarif pelayanan jasa Kapal yang melakukan kegiatan angkutan laut luar negeri dikenakan tarif jasa kepelabuhanan dalam mata uang Dollar Amerika Serikat (US \$) dengan pembayaran menggunakan mata uang Rupiah (Rp), kecuali ditentukan lain oleh peraturan perundang-undangan.

a) Kapal Lokal

Nama Kapal

: MT. AS MARINE SATU (Bendera Indonesia)

GRT (Gross Tonn)

: 2,499 GT 
Muatan

: CPO (Oil)

Kapal Tiba

: 16 April 2020

Kapal Berangkat

: 19 April 2020

Kapal melakukan proses bongkar/muat barang di Kade 005 yaitu milik perusahaan

Samudera Indonesia

Biaya Pelabuhan yang timbul saat kapal sandar:

1) Biaya Tarif Pelabuhan

Labuh

$$
\begin{aligned}
& =\text { Tarif Pelabuhan x GRT } \\
& =\operatorname{Rp} 90 \times 2,499 \mathrm{GT} \\
& =\operatorname{Rp} 224,910
\end{aligned}
$$

Jasa Tambat MASA I 16-04-2020 11:50 - 18-04-202011:50

$=$ Pergerakan Kapal $\mathrm{x}$ Tarif Pelabuhan $\mathrm{x}$ GRT

$=2$ pergerakan $\times \mathrm{Rp} 105 \times 2,499$ GT

$=\operatorname{Rp} 524,790$

Jasa Pandu (Masuk)

(Tarif Tetap ) = Tarif Pelabuhan / Gerakan

$=\operatorname{Rp} 213,248 /$ Gerakan

$=$ Rp. 213,248

(Tarif Tambahan) = Tarif Pelabuhan $\mathrm{x}$ GRT

$=\operatorname{Rp} 59.20 \times 2,499 \mathrm{GT}$

$=\operatorname{Rp} 127,941$

Sub total biaya pandu (masuk)

$=$ Tarif Tetap + Tarif Tambahan

$=\operatorname{Rp} 213,248+\operatorname{Rp} 127,941$

$=\operatorname{Rp} 341,189$

Jasa Tunda (Masuk)

(Tarif Tetap) = = Waktu Kapal Tunda $\mathrm{x}$ Tarif Pelabuhan

$=3 \times \operatorname{Rp} 505.92$

$=\operatorname{Rp} 1,517,760$

(Tarif Variabel) = Waktu Kapal Tunda $\mathrm{x}$ Tarif Pelabuhan $\mathrm{x}$ GRT

$=3 \times \mathrm{Rp} 8.00 \times 2,499 \mathrm{GT}$

$=\operatorname{Rp} 59,976$

Sub total biaya tunda (masuk)

$=$ Tarif Tetap + Tarif Variabel

$=\operatorname{Rp} 1,517,760+\operatorname{Rp} 59,976$ 
$=\operatorname{Rp} 1,577,736$

Tarif Kepil / Mooring

$=\operatorname{LOA}(\mathrm{M})($ Ukuran panjang kapal $)>100<150$

= Rp. 409,500 (Berdasarkan ketentuan Tarif Pelabuhan )

Jasa Pandu (Keluar)

(Tarif Tetap ) = Tarif Pelabuhan $/$ Gerakan

$=$ Rp.213,248 / Gerakan

$=$ Rp. 213,248

(Tarif Tambahan) = Tarif Pelabuhan $\mathrm{x}$ GRT

$=$ RP. $59.20 \times 2,499 \mathrm{GT}$

$=$ Rp. 147,941

Sub total biaya pandu (keluar)

$$
\begin{aligned}
& =\text { Tarif Tetap }+ \text { Tarif Variabel } \\
& =\operatorname{Rp} 213,248.00+\operatorname{Rp~127,941.00} \\
& =\operatorname{Rp} 361,189
\end{aligned}
$$

Jasa Tunda (Keluar)

(Tarif Tetap) = = Waktu Kapal Tunda $\mathrm{x}$ Tarif Pelabuhan

$=2.5 \times \operatorname{Rp} 505.92$

$=\operatorname{Rp} 1,264,800$

(Tarif Variabel) = Waktu Kapal Tunda $\mathrm{x}$ Tarif Pelabuhan $\mathrm{x}$ GRT

$$
=2.5 \times \text { Rp. } 8.00 \times 2,499 \mathrm{GT}
$$$$
=\operatorname{Rp} 49,980
$$

Sub total biaya tunda (keluar)

$=$ Tarif tetap + Tarif Variabel

$=\operatorname{Rp} 1,264,800.00+\operatorname{Rp} 49,980.00$

$=\operatorname{Rp} 1,314,780$

Total Jasa Tambat, Pandu dan Tunda 
$=$ Biaya Tambat + Mooring + Sub total Pandu(masuk $)+$ Sub total Tunda(masuk) + Sub total Pandu(keluar) + Sub total Tunda (keluar) + PPN $10 \%$

$=\operatorname{Rp} 524,790+\operatorname{Rp} 409,500+R p 341,189+\operatorname{Rp} 1,577,736+\operatorname{Rp} 361,189+$ Rp1,314,780 + PPN 10\%

$=4.549 .184+\operatorname{Rp} 454,919$

$=\operatorname{Rp} 5,004,103$

Biaya Sampah Kapal $=$ Tarif Dalam Negeri Rp. 150,000 $/$ minimal $3 M^{3}$

$$
\begin{aligned}
& =\text { Volume } 3 \times \text { Tarif Pelabuhan } \\
& =3 \times \operatorname{Rp} 50,000 \\
& =\operatorname{Rp} 150,000
\end{aligned}
$$

b) Kapal Asing

Nama Kapal

GRT (Gross Tonn)

: MT. WOOJIN KELLY (Bendera Korea)

Muatan

: $8,254 \mathrm{GT}$

Kapal Tiba

: CPO (Oil)

Kapal Berangkat

: 21 May 2020

Exchange Rate

: 21 May 2002

Kapal melakukan proses bongkar/muat barang di Kade 005 yaitu milik perusahaan Samudera Indonesia

Biaya Pelabuhan yang timbul saat kapal sandar:

$$
\begin{aligned}
\text { Labuh } & =\text { Tarif Pelabuhan } \times \text { GRT } \\
& =\operatorname{Rp~} 1518 \times 8,254 \mathrm{GT} \\
& =\frac{\operatorname{Rp} 12,529,572}{\text { E.R } 14.785} \\
& =\text { USD } 875.45
\end{aligned}
$$

Jasa Pandu (Masuk)

$$
\begin{array}{ll}
(\text { Tarif Pokok }) & =\text { Tarif Pelabuhan } / \text { Gerakan } \\
& =\text { USD } 75.00 / \text { Gerakan } \\
& =\text { USD } 75.00 \\
\text { (Tarif Tambahan) } & =\text { Tarif Pelabuhan } \times \text { GRT } \\
& =\text { USD } 0.022 \times 8,254 \text { GT } \\
& =\text { USD } 181.59
\end{array}
$$


Sub total biaya pandu (masuk)

$=$ Tarif Pelabuhan $/$ Gerakan

$=$ USD $75.00+$ USD 181.59

$=$ USD 256.59

Jasa Tunda (Masuk)

(Tarif Tetap) = = Waktu Kapal Tunda $\mathrm{x}$ Tarif Pelabuhan

$$
=3 \times \text { USD } 641.250
$$$$
=\text { USD } 1,923.75
$$

(Tarif Variabel) = Waktu Kapal Tunda $\mathrm{x}$ Tarif Pelabuhan $\mathrm{x}$ GRT

$$
\begin{aligned}
& =3 \times \text { USD } 0.005 \times 8,254 \text { GT } \\
& =\text { USD } 123.81
\end{aligned}
$$

Sub total biaya tunda (masuk)

$=$ Tarif Tetap + Tarif Variabel

$=$ USD $1,923.75+$ USD 123.81

$=$ USD 2,047.56

Tarif Kepil / Mooring

$=$ LOA $($ M $)($ Ukuran panjang kapal $)>200<$ UP

$=$ USD 117.00 (Berdasarkan ketentuan Tarif Pelabuhan $)$

Jasa Pandu (Keluar)

(Tarif Pokok) = Tarif Pelabuhan $/$ Gerakan

$=$ USD $75.00 /$ Gerakan

$=\operatorname{USD} 75.00$

(Tarif Tambahan) $=$ Tarif Pelabuhan $\mathrm{x}$ GRT

$=$ USD $0.022 \times 8,254 \mathrm{GT}$ 


$$
=\text { USD } 181.59
$$

Sub total biaya pandu (masuk)

$=$ Tarif Pelabuhan / Gerakan

$=$ USD $75.00+$ USD 181.59

$=$ USD 256.59

Jasa Tunda (Keluar)

(Tarif Tetap) = Waktu Kapal Tunda $\mathrm{x}$ Tarif Pelabuhan

$=2.5 \times$ USD 641.250

$=$ USD $1,603.13$

(Tarif Variabel) = Waktu Kapal Tunda $\mathrm{x}$ Tarif Pelabuhan $\mathrm{x}$ GRT

$=2.5 \times$ USD $0.005 \times 8,254 \mathrm{GT}$

$=$ USD 103.175

Sub total biaya tunda (keluar)

$=$ Tarif tetap + Tarif Variabel

$=$ USD 1,603.13 + USD 103.175

$=$ USD 1,706.305

Total Jasa Tambat, Pandu dan Tunda

$=$ Biaya Tambat + Mooring + Sub total Pandu(masuk $)+$ Sub total Tunda(masuk $)+$ Sub total Pandu(keluar) + Sub total Tunda (keluar)

$$
\begin{aligned}
& =\text { USD } 256.59+\text { USD 2,047.56 + USD } 117.00+\text { USD 256.59 + USD 1,706.305 } \\
& =\text { USD 4,384.045 }
\end{aligned}
$$

Biaya Sampah Kapal = = Tarif Dalam Negeri Rp. 150,000/minimal $3 M^{3}$

$$
=\text { Volume } 3 \times \text { Tarif Pelabuhan }
$$$$
=3 \times \text { USD } 15
$$$$
=\text { USD } 65
$$ 


\begin{tabular}{|l|l|l|}
\hline \multirow{2}{*}{ Tarif biaya } & \multicolumn{2}{|c|}{ Jenis kapal } \\
\cline { 2 - 3 } & Kapal nasional & Kapal asing \\
\hline Labuh & 224,910 & $12,529,572$ \\
\hline JASA PANDU TUNDA, TAMBAT & $5,004,103$ & $64,285,845$ \\
\hline BIAYA SAMPAH KAPAL & 150,000 & 668,652 \\
\hline
\end{tabular}

Tarif jasa pelabuhan terjadi karena ada pihak yang memberikan/menyediakan pelayanan (oleh penyelenggara pelabuhan) oleh sebab itu tarif harus jelas besarannya, jenis pelayanan yan diberikan/disediakan dan bagaimana pemberlakuannya.

Besarnya tarif jasa kepelabuhanan di tetapkan (diatur dalam PP 61 tahun 2009 tentang kepelabuhanan pasal 146) kepentingan pelayanan umum, peningkatan mutu pelayanan jasa kepelabuhanan, kepentingan pengguna jasa, peningkatan kelancaran pelayanan jasa, pengembalian investasi serta pengembangan usaha. Tarif jasa kepelabuhanan harus ada keseimbangan antara besaran tarif dengan tingkat pelayanan yang diterima oleh pengguna jasa, meliputi keselamatan, keamanan, kelancaran dan kenyamanan.

Jenis Penerimaan Negara Bukan Pajak yang berasal dari jasa transportasi laut berupa hasil konsesi dan/atau kompensasi atas pelayanan jasa kepelabuhanan di pelabuhan. Tarif pelayanan jasa Kapal yang melakukan kegiatan angkutan laut dalam negeri dikenakan tarif jasa kepelabuhanan dalam mata uang Rupiah (Rp). Sedangkan Tarif pelayanan jasa Kapal yang melakukan kegiatan angkutan laut luar negeri dikenakan tarif jasa kepelabuhanan dalam mata uang Dollar Amerika Serikat (US \$) dengan pembayaran menggunakan mata uang Rupiah (Rp), kecuali ditentukan lain oleh peraturan perundang-undangan.

Dengan data diatas kita dapat menganalisa apa saja perbandingan biaya yang timbul saat kapal sandar sehingga dapat mengetahui bagaimana faktor penyebab adanya perbandingan biaya sandar kapal untuk kapal nasional dan kapal asing.

1. Faktor Surcharge

Surcharge adalah sejumlah biaya tambahan yang di bebankan kepada customer dan di bayarkan langsung kepada pihak merchant karena ada nya musim libur panjang atau long weekend. Biaya yang di maksud seperti biaya koordinasi Petugas KSOP(Kantor Kesyahbandaran Dan Otoritas Pelabuhan). Besaran surcharges antara 10 hingga 25 persen, sehingga cukup membebani biaya logistik pelabuhan, yang secara nasional berdampak pada indeks prestasi logistik Indonesia yang saat ini masih dikisaran 59 dari 150 negara sedunia, seperti penilaian Bank Dunia, sebelumnya. Masih adanya pungutan surcharges pelayaran asing itu, ditengarai 
menjadikan Pelabuhan Indonesia termahal di Asia Tenggara, bahkan mungkin se dunia.

\section{Dibawah ini simulasi biaya pelabuhan}

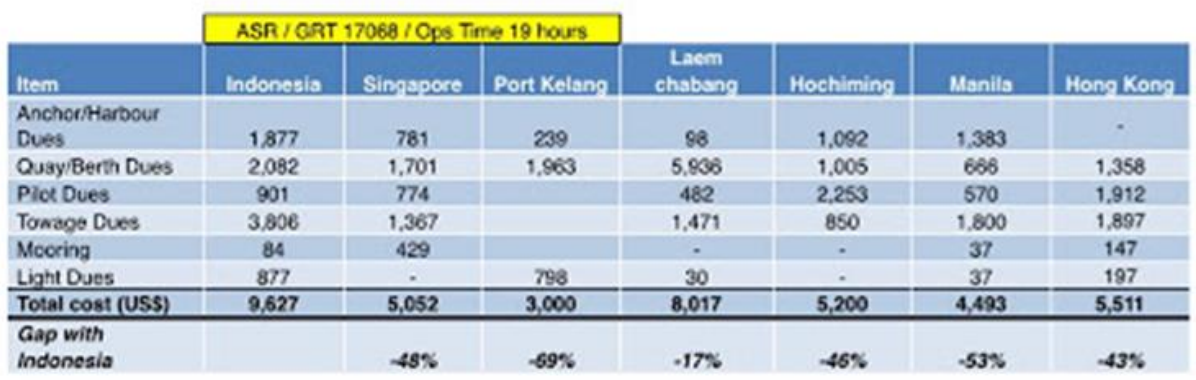

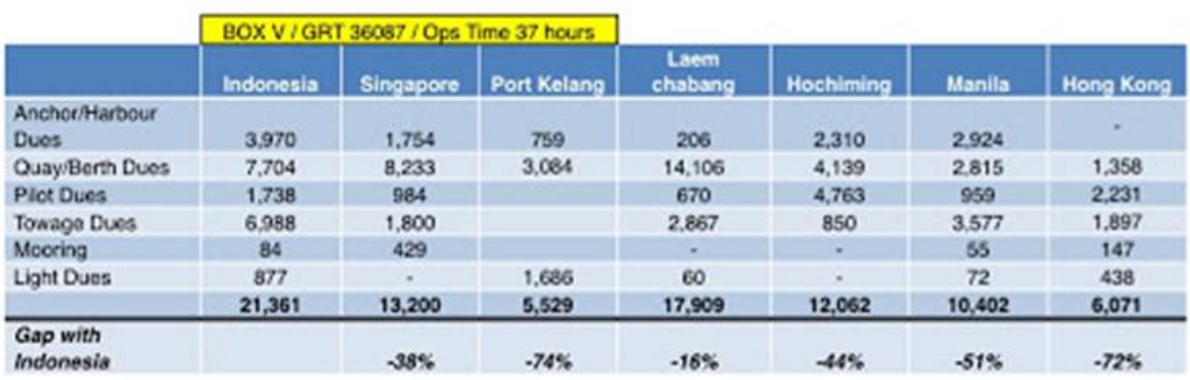

2. Faktor Pelayanan

Dalam mendorong iklim investasi dan menciptakan tarif jasa kepelabuhanan yang efisien dan kompetitif perlu dilakukan penataan kembali jenis struktur, golongan dan mekanismen penetapan tarif jasa kepelabuhanan. Namun dapat diketahui juga bahwa biaya pengiriman logistik di indonesia masih terbilang mahal karena pelayanan di pelabuhan belum efisien sehingga untuk mendapat kepuasan pelanggan / pengguna jasa pelabuhan masih mengenakan tarif yang lebih besar untuk setiap kegiatannya.

3. Faktor Dwelling Time

Dwelling Time adalah proses waktu peti kemas di bongkar atau muat dari kapal dan akan di timbun di tempat penimbunan sementara (TPS) di pelabuhan sampai barang tersebut keluar dari tempat penimbunan sementara. Fasilitas pelabuhan yang kurang memdai menjadi salah satu faktor penyebab adanya waktu tunggu kapal, Sehingga akan adanya biaya tambahan karena penumpukan muatan yang lama di pelabuhan. 


\section{Simpulan}

Berdasarkan hasil penelitian dan hasil data mengenai perbandingan tarif biaya pelabuhan untuk kapal nasional dan kapal asing di pelabuhan Tanjung Priok yang telah dilakukan, dapat disimpulkan :

Setiap kepemilikan kapal asing harga tarif sudah jelas berbeda, terlihat dari tabel perbandingan tarif biaya kapal nasional dan kapal asing. Oleh karena itu biaya untuk kapal nasional dan kapal asing tidak bisa di bandingkan karena biaya kapal asing yang tiba di indonesia sudah di sesuaikan dengan tarif asing yang memang di perhitungkan untuk biaya asing yang tidak bisa di bandingkan dengan kapal nasional.

\begin{tabular}{|l|l|c|}
\hline \multirow{2}{*}{ Tarif biaya } & \multicolumn{2}{|c|}{ Jenis kapal } \\
\cline { 2 - 3 } & Kapal lokal & Kapal asing \\
\hline Labuh & 224,910 & $12,529,572$ \\
\hline JASA PANDU TUNDA, TAMBAT & $5,004,103$ & $64,285,845$ \\
\hline BIAYA SAMPAH KAPAL & 150,000 & 668,652 \\
\hline
\end{tabular}

Adapun faktor yang mempengaruhi perbandingan tarif biaya pelabuhan antara lain Adapun faktor yang mempengaruhi perbandingan tarif biaya pelabuhan antara lain

1. Faktor Surcharge

Adanya sejumlah biaya tambahan yang di bebankan kepada customer dan di bayarkan langsung kepada pihak. Besaran surcharges antara 10 hingga 25 persen, sehingga cukup membebani biaya logistik pelabuhan,

2. Faktor Pelayanan

Biaya pengiriman logistik di indonesia masih terbilang mahal karena pelayanan di pelabuhan belum efisien sehingga untuk mendapat kepuasan pelanggan / pengguna jasa pelabuhan masih mengenakan tarif yang lebih besar untuk setiap kegiatannya.

3. Faktor Dwelling Time

Fasilitas pelabuhan yang kurang memadai menjadi salah satu faktor penyebab adanya waktu tunggu kapal, Sehingga akan adanya biaya tambahan karena penumpukan muatan yang lama di pelabuhan.

\section{E. Daftar Pustaka}

[FT] Fakultas Teknik. 2019. Buku Panduan Penyusunan Tugas Akhir .Jakarta. Fakultas Teknik, Universitas Negeri Jakarta

Hadi. Winoto,ST.MT \& Ali Sungkono MBA,MM, MSc. 2018 Pelayanan Pelanggan. Jakarta. Fakultas Teknik. Universitas Negeri Jakarta.

Keputusan Menteri Perhubungan No. KM. 57 tahun 2006 Tentang Mekanisme Penetapan dan Formulasi Perhitungan Tarif Angkutan Penumpang Laut Dalam Negeri.

Lasse, D.A. (2016) Manajemen Kepelabuhanan. Ed - ke2 Jakarta: Rajawali Pers.

Pemerintah Republik Indonesia. 2008. Undang - Undang Nomor 17 Tahun 2008 
Tentang Pelayaran.

Peraturan Pemerintah Nomor 61 tahun 2009. Tentang Kepelabuhanan.

Peraturan Menteri Perhubungan No 63 Tahun 2010 Tentang Standar Kinerja Operasional Kapal Angkutan Laut Dalam dan Luar Negeri untuk Pelayanan

Peraturan Pemerintah Nomor 64 Tahun 2015 tentang Perubahan Atas Peraturan Pemerintah Nomor 61 Tahun 2009 tentang Kepelabuhanan.

Peraturan Menteri Perhubungan Republik Indonesia Nomor PM No 72 Tahun 2017 Tentang Jenis, Struktur, Golongan Dan Mekansme Penetapan Tarif Jasa Kepelabuhanan 